\title{
A DANÇA DOS NOMES: ANÁLISE DE UM NOME PRÓPRIO NA CENA DE FAROESTE CABOCLO
}

\author{
Cláudia Aparecida de Oliveira Leite ${ }^{1}$
}

Résume: Dans ce travail on analyse un nom propre dans la parole de la musique Faroeste Caboclo en soutenant l'hypothèse qui une renomination identifie de façon diffèrente le nommé et alors en établissant des prédications variantes. Les nuances qui sont mis en jeu dans le procès d'identification permis que, pour désignation de une même personne circule attributs différents, divergents et mutables. De cette façon, on a considéré qui le fonctionnement du nom propre de personne interroge les différents positions théoriques qui soutane la Linguistique.

Mots-clés: Nom propre; Linguistique; Sémantique.

Resumo: Neste trabalho analisamos um nome próprio na letra de Faroeste Caboclo sustentando a hipótese de que uma renomeação identifica diferentemente o nomeado ao estabelecer predicações variantes e que as nuances que estão em jogo no processo de identificação permitem que, pela designação de uma mesma pessoa, transitem atributos variados, divergentes e mutáveis. Assim, consideramos que o funcionamento do nome próprio de pessoa interroga as diversas posições teóricas que sustentam a Lingüística.

Palavras-chaves: Nome próprio; Lingüística; Semântica.

\section{INTRODUĔ̃̃O}

O objetivo do presente trabalho é analisar o nome próprio do personagem principal da música Faroeste Caboclo e as reescrituras desse nome no texto. Esta música foi lançada em dezembro de 1987 dentro do álbum intitulado Que país é esse?. Escrita em 1979, Faroeste Caboclo contém 159 versos, alcançando mais de nove minutos de duração.

Considerando que a cada ato de nomeação temos diferenças no funcionamento dos nomes próprios, nos lançamos a analisar o nome próprio da música supra citada, salientando a importante carga sócio-política que marcou o período que vai da escrita à execução dessa música e que coincide com a descarga musical que chega ao cenário nacional pelos acordes do Rock Brasileiro $^{2}$ dos anos 80.

Partimos da hipótese, neste trabalho, de que o contexto histórico que embalava o Brasil foi profundamente cantado/contado nas letras do chamado

\footnotetext{
${ }^{1}$ Doutoranda em Lingüística IEL/UNICAMP, Bolsista da CAPES.

2 Rock Brasileiro também recebe a designação de BRock.
} 
Rock Brasileiro e que, nessa modalidade enunciativa, os nomes próprios dos personagens das músicas possuem sentidos específicos. Para o presente trabalho nos deteremos na análise do nome dentro da letra de Faroeste Caboclo, levando em conta o que é construído historicamente e que assegura sua enunciação. Consideramos, ainda, a hipótese de que uma renomeação identifica diferentemente o nomeado ao estabelecer predicações variantes.

Salientamos, entretanto, que será pertinente, em trabalhos futuros, efetuar essa análise comparativamente pesquisando as letras de música desse mesmo estilo (rock), e buscando algo comparável em outros compositores, como por exemplo, Raul Seixas que mantém algumas características em comum com Renato Russo, líder da banda de rock Legião Urbana.

Para a análise que propomos em Faroeste Caboclo estamos considerando, juntamente com Guimarães (2002), o nome próprio ligado ao sujeito, à enunciação e à história, seguindo uma reflexão enunciativa para problemas de designação e referência na línguagem.

Guimarães considera que não há como pensar uma semântica lingüistica sem levar em conta que o que se diz é incontornavelmente construído na línguagem ${ }^{3}$. É no espaço conformado por estas duas necessidades, quais sejam, de que a línguagem fala de algo e do construído na línguagem, que ele procura configurar o que é uma semântica do acontecimento - uma semântica que considera que a análise do sentido da línguagem deve localizar-se no estudo da enunciação, no acontecimento do dizer.

Dessa forma, Guimarães sustenta que o tratamento da enunciação deve dar-se num espaço em que seja possível considerar a constituição histórica do sentido, de modo que a semântica se formule, claramente, como uma disciplina do campo das Ciências Humanas, fora de suas relações com a lógica ou gramática matematizável ou de uma gramática que apresenta uma estrutura biologicamente determinada.

O que o nome designa é construído simbolicamente, afirma Guimarães. Dessa forma, a referência resulta do sentido do nome constituído por seu funcionamento no acontecimento enunciativo. Não é um sujeito que nomeia, ou refere, nem a expressão, mas o acontecimento, exatamente porque esse acontecimento constitui seu próprio passado. Assim, ele marca que este tipo de consideração do funcionamento da designação, nomeação e referência coloca absolutamente em xeque qualquer tentativa de tratamento composicional do sentido. Ele relaciona essa impossibilidade ao fato de que a relação integrativa de uma expressão deve ser remetida à textualidade e não às relações imediatas e segmentais num enunciado. $E$ isto se liga diretamente ao

${ }^{3}$ Guimarães (2002), p.7. 
caráter próprio do funcionamento politico da línguagem no acontecimento da enunciação. ${ }^{4}$

Atentos aos aportes teóricos elaborados por Guimarães, traremos, a seguir, alguns desdobramentos políticos e sociais que marcaram a história brasileira nos contornos dos anos 80 para, em seguida, fazermos a análise que propomos.

\section{A ESEOLHA DESSA COMPOSIĢ̃̃̃O MUSICAL}

Considerando o acontecimento enunciativo como o que marca o nome próprio, ressaltaremos a peculiaridade em analisar um nome dentro de uma composição musical e, mais especificamente no momento sócio-político brasileiro dos anos 80. Julgamos provável que os nomes próprios, nesse contexto, convocam predicados que são profundamente condizentes com os posicionamentos sociais daquele momento; dessa forma, os nomes próprios nas letras das músicas do Rock Brasileiro dos anos 80 participavam da trama simbólica que perpassava a história e a política brasileira. E também nesse momento, o Rock Brasileiro se consolidava no cenário musical de maneira consistente.

Segundo Dapieve:

Até os anos 80 , a marginalidade do BRock era outra. Nem em seu momento de maior sucesso popular, a Jovem Guarda, ele conseguiria deixar de ser tratado, por quase todos, inclusive por alguns de seus cultores, como uma febre passageira, que logo os glóbulos verde-eamarelos se encarregariam de expulsar do corpo da música brasileira, devolvendo-lhe assim sua sanidade. Estrangeiro numa nação de estrangeiros, o rock penou quase três décadas até conseguir, de fato e de direito, a cidadania brasileira.

O Brasil, que foi governado por um regime militar ${ }^{5}$ desde o golpe de estado de 31 de março de 1964 até março de 1985, se lança em um gradual processo de "abertura política" que culmina na Redemocratização. Nessa trama política, o crescimento das oposições nas eleições de 1978, em que foi eleito o General João Baptista Figueiredo (que governa de 1979 a 1985), acelera o processo de abertura. A Lei da Anistia, aprovada em 28 de agosto de 1979, é um fato de grande importância para os desdobramentos dessa redemocratização.

\footnotetext{
${ }^{4}$ Guimarães (2002), p. 94

5 Plano político marcado pelo autoritarismo, supressão dos direitos constitucionais, perseguição policial e militar, prisão e tortura dos opositores, censura prévia aos meios de comunicação. Sobre o tema ver: GASPARI, E. A ditadura envergonhada Companhia das Letras, SP, 2002 e GASPARI, E. A ditadura escancarada. Companhia das Letras, SP, 2002.
}

50 VOLUME 2, NÚMERO 2, 2006 
No processo de Redemocratização, os militares insistem em controlar a transição do governo e articulam para que a sucessão do General Figueiredo, pela eleição de novembro de 1984, fosse feita por eleições indiretas. Diante da articulação dos militares, os movimentos sociais se unem em torno da campanha das Diretas Já propondo que o voto fosse direto. Entretanto, essa emenda foi derrotada no congresso. Dessa forma, Tancredo Neves é eleito em 15 de janeiro de 1985 sendo o primeiro presidente civil depois de 21 anos de ditadura militar. Embora as eleições tenham sido indiretas, a sociedade recebeu com otimismo a eleição de Tancredo, que morreu antes de assumir a presidência. Quem assume é o Vice-presidente José Sarney.

A última eleição indireta marca o fim do Regime Militar, mas a transição para a democracia continuava operando por outros acontecimentos, tal como a promulgação da nova Constituição Brasileira em 1988 no governo de José Sarney.

Porque escolher analisar Faroeste Caboclo? Ao descrever esta música, Dapieve (1995) nos indica alguns detalhes que realçam suas especificidades:

... sua quilométrica letra - 159 versos! - narra paixão e morte de um certo João de Santo Cristo, misto de traficante e homem santo (uma espécie de Brasil personificado). Esta saga começava como música sertaneja, passava pelo reggae e terminava em punk rock $\ldots$

Legião Urbana se configurou como uma das principais bandas de rock dos anos 80, emplacando vários sucessos no primeiro lugar do hit parade das AMs e FMs, superando a expectativa de venda dos seus discos e conquistando ampla circulação popular. Renato Russo ${ }^{6}$, seu líder, se tornou um ícone, um mito imortalizado pelas letras que mesclavam poesia, ousadia e irreverência. Precisamente em Faroeste Caboclo encontramos as marcas políticas, pensadas como a afirmação da igualdade, do pertencimento do povo ao povo, em conflito com a divisão desigual do real". No momento de "abertura política" a banda canta a história do sub-emprego, do tráfico, da violência, da fome, da mídia e ainda, lança um palavrão aos ouvidos da censura oscilante sobre os meios de comunicação cultural e social. Encontramos, ainda, o procedimento de renomeação operando e mesclando predicados como veremos na descrição que segue.

${ }^{6}$ Renato Russo faleceu em 11 de outubro de 1996.

${ }^{7}$ Guimarães (2002), p.17. 


\section{ANÁLISE DO NOME PRÓPRIO EM SUA RELAĢ̃̃ ENUNGIATIVA}

O texto de uma música apresenta uma circulação peculiar e configura uma cena enunciativa específica. Tomamos aqui o conceito de cena enunciativa conforme definido por Guimarães (2002) em que cenas são especificações locais nos espaços de enunciação ${ }^{8}$. Assim:

Uma cena enunciativa se caracteriza por constituir modos específicos de acesso à palavra dadas as relações entre as figuras da enunciação e as formas lingüísticas ${ }^{9}$.

Analisaremos o nome próprio do personagem João de Santo Cristo, em torno de quem se passa a narração do texto ${ }^{10} \mathrm{e}$, em seguida, consideraremos os memoráveis que este nome próprio recorta. Vejamos:

\begin{tabular}{|r|l|}
\hline $\begin{array}{r}\text { João de Santo Cris- } \\
\text { to }\end{array}$ & $\begin{array}{l}\text { Nome (João) + preposição (de) + Nome (Cristo) precedido de titula- } \\
\text { cão (Santo) }\end{array}$ \\
\hline Ele & $\begin{array}{l}\text { Pronome pessoal; anáfora; reescrita com "certa aparência" de neu- } \\
\text { tralidade; reescreve os três nomes do texto. }\end{array}$ \\
\hline João & $\begin{array}{l}\text { Primeiro nome, que permite diferenciá-lo no grupo. Nome próprio de } \\
\text { grande circulação social. }\end{array}$ \\
\hline Santo Cristo & $\begin{array}{l}\text { Sobrenome composto por um nome próprio (Cristo) precedido da } \\
\text { titulação (Santo) expedida pela instituição lgreja; marca o rito salvador } \\
\text { do personagem, prenunciando sua glória, paixão e morte. }\end{array}$ \\
\hline
\end{tabular}

Em João de Santo Cristo há uma enunciação que nomeia alguém João e uma enunciação bíblica tomada pela Igreja que nomeia alguém Santo pelo ato de santificação, por um performativo. O santo nomeado é Cristo, que recorta outros memoráveis, retomando a figura religiosa que é o Filho amado de Deus, o Cordeiro de Deus e o Salvador do mundo. Há um batismo inicial que traz o nome completo do personagem e é importante notar que as reescrituras que encontramos são partes dessa primeira nomeação.

Conforme aponta Guimarães ${ }^{11}$ :

No caso da relação entre designação e referência, o que se deve buscar é como um nome aparece referindo no texto em que ocorre. Assim é fundamental observar como 0 nome está relacionado pela textualidade com outros nomes ali funcionando sob a apa

8 Guimarães (2002), p.23

9 Guimarães (2002), p.23

10 Outros personagens são referidos na trama de Faroeste Caboclo: Um Boiadeiro, Pablo, Jeremias, Maria Lúcia, Um Senhor de Alta Classe.

11 Guimarães (2002), p.27

52 VOLUME 2, NÚMERO 2, 2006 
rência da substituibilidade. Neste caso, os conjuntos de modos de referir organizados em torno de um nome são um modo de determiná-lo, de predicá-lo.

A aparente substituibilidade que a reescritura do nome próprio nos fornece, pode ser confrontada com as predicações que podemos destacar:

1) João de Santo Cristo

- Não tinha medo

- Deixou pra trás todo marasmo da fazenda

- Só pensava em ser bandido

- Era o terror da cercania onde morava

- Ia ... roubar o dinheiro

- Era diferente

- Comia todas menininhas da cidade

- Foi mandado pro reformatório

- Não entendia como a vida funcionava

- Ficou cansado de tentar achar resposta

- Ficou rico

- Fez amigos

- Freqüentava a Asa Norte

- Começou a roubar

- Era santo porque sabia morrer

Ele (anáfora de João de Santo Cristo)

- Se perdeu

- O professor com ele aprendeu

- Queria sair para ver o mar e as coisas que ele via na televisão

- Escolheu a solidão

- No primeiro roubo ele dançou e pro inferno ele dançou pela primeira vez.

2) João

- João foi lhe salvar

- Aprendiz de carpinteiro

- Ia pra zona da cidade gastar todo seu dinheiro de rapaz trabalhador.

- Não boto bomba em banca de jornal e em colégio de criança

- Não protejo general de 10 estrelas

- Olhou as bandeirinhas

- Seu protetor

- Não conseguiu o que queria

Ele (anáfora de João) 
- Ele ficou bestificado com a cidade

- Ele queria era falar com o presidente pra ajudar toda essa gente que só faz sofrer.

\section{3) Santo Cristo}

- Até a morte trabalhava

- Era bandido destemido e temido

- Conheceu uma menina; prometeu o coração dele pra ela

- Futuro incerto

- Se embebedou

- Revendia contrabando em Planaltina

- Era só ódio por dentro

- Não sabia o que fazer

- Deu 5 tiros no bandido traidor

Ele (anáfora de Santo Cristo)

- O dinheiro não dava pra ele se alimentar

- Não queria mais conversa

- Iria se virar

- Elaborou seu plano santo

- Se arrependeu [de todos seus pecados]

- Ele dizia que queria se casar

- Carpinteiro ele voltou a ser

- Não foi trabalhar

- Ele chorou

- Ele foi pro inferno pela segunda vez

Considerando agora uma análise conforme o Domínio Semântico de Determinação (DSD) proposto por Guimarães, em que as palavras têm seu sentido construído nas suas relações com outras palavras no enunciado, podemos analisar o nome próprio João de Santo Cristo considerando os dois procedimentos fundamentais que, segundo Guimarães, são constitutivos da enunciação: 1) o procedimento de reescrituração; 2) procedimento de articulação. Guimarães (2004) define a reescrituração como o procedimento pelo qual a enunciação de um texto rediz insistentemente o que já foi dito fazendo interpretar uma forma como diferente de si. Este procedimento atribui (predica) algo ao escriturado.

No movimento de renomeação que reescreve qualificando e especificando, podemos apontar que o procedimento de reescrituração pode ser destacado, nessa letra, pelas renomeações do nome próprio João de Santo Cristo. Con 
forme já salientamos, o personagem recebe seu batismo logo no início da música e seu nome é reescrito como ele, João, Santo Cristo. A circulação das predicações por entre esses nomes nos apontam diferenças relevantes na forma como o personagem é predicado. Nas renomeações percebemos a caracterização pendular que faz oscilar o caráter protetor (salvador) / bandido do personagem. Esse movimento pendular percorre sua saga e marca sua morte.

Tais renomeações marcam diferentes lugares enunciativos no texto e alcançam seu topo pelo procedimento de articulação. Os vários movimentos do personagem nos deixam a impressão de que se trata de várias pessoas, dessa maneira, há uma fenda no funcionamento do nome próprio como aquele que permite uma unidade do objeto. Cada reescritura apresenta um "personagem" com predicados distintos.

Os procedimentos de articulação correspondem às relações próprias das contigüidades locais e marcam as relações de determinação. As predicações determinam os nomes, atribuem a eles características que diferenciam e igualam o personagem, carregando para o texto as marcas da diferença ao mesclar qualidades possivelmente entendidas como opostas. Esse fato ocorre entre as três nomeações e dentro de uma mesma.

Nas relações de determinação ${ }^{12}$, podemos dizer, considerando as predicações indicadas anteriormente, que:
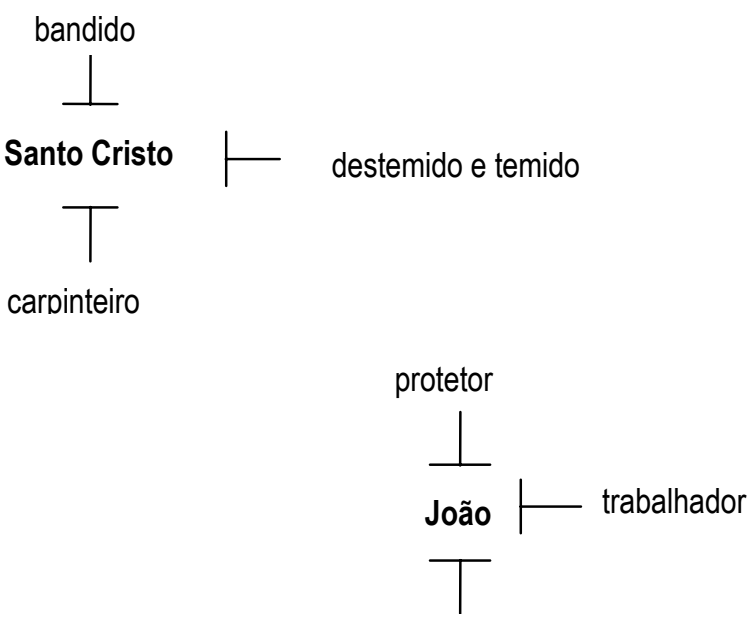

(ele) queria era falar com o presidente pra ajudar toda essa gente

\footnotetext{
12 Em que podemos ler $X-1 Y$, como $X$ determina $Y$.
} 
Enquanto bandido determina João de Santo Cristo $e$ Santo Cristo, protetor determina João. O funcionamento do nome próprio de pessoa interroga as posições referencialistas, interroga as que consideram o nome próprio pleno de sentido ou vazios de sentido e questiona aquelas que tomam o nome próprio como indutor de uma unidade. As nuances que estão em jogo no processo de identificação permitem que pela designação de uma mesma pessoa transitem atributos variados, divergentes e mutáveis.

\section{CONSIDERACÕ̃ES FINAIS}

Esse misto oscilante de salvador e bandido, que num instante sofria as desigualdades sociais e noutro freqüentava o circuito "burguês", marca os nomes próprios de Faroeste Caboclo. As relações de determinação que estão em jogo nos nomes próprios da música apresentam uma dispersão nas predicações. Há uma perda da unidade e do caráter indicativo do nome próprio; os predicados dançam se tornando, em alguns pontos, contraditórios. Destacamos o predicado bandido que é um atributo de João de Santo Cristo e Santo Cristo, mas não predica João, que recebe o atributo de protetor. Sustentamos, portanto, que a renomeação identifica diferentemente ao predicar de maneira distinta.

Em que medida podemos pensar que essas especificidades ocorrem embaladas pelos movimentos sociais e políticos que ordenavam a abertura política brasileira? Supomos que o caráter subversivo e contraditório do personagem da música aqui discutida, pode ser encontrada em outras músicas do Rock Brasileiro dos anos 80 embaladas pelos movimentos históricos que foram vivenciados pela sociedade naquele período. Os nomes próprios que compõem essas músicas tornam-se verdadeiros vetores enunciativos.

Os nomes próprios nas músicas do BRock dos anos 80 designam personagens que pedem voz e vez e que criticam a desigualdade, a violência, a mídia, o pouco investimento social. Como traço comparativo, para ancorar essa conclusão, podemos apontar a rebeldia e a crítica ao sistema que também compôs as músicas de Raul Seixas, mas que sustentam uma enunciação distinta.

Os nomes próprios não funcionam da mesma forma em todos os agenciamentos enunciativos, isso quer dizer que, a cada enunciação e em cada acontecimento, eles apresentam uma tessitura específica a cada coisa nomeada.

\section{BIBLIOGRAFIA}

DAPIEVE, Arthur. Brock: o rock brasileiro dos anos 80. Rio de Janeiro, Ed.34, 1995.

GUIMARÃES, Eduardo. Civilização na Lingüística Brasileira no século XX, (Submetido à Revista Matraga), 2004.

56 VOLUME 2, NÚMERO 2, 2006 
GUIMARÃES, Eduardo. Semântica do Acontecimento: um estudo enunciativo da designacãão. Campinas, Pontes, 2002.

LEITE, Cláudia A.O. O nome próprio e sua relação com o inconsciente. Dissertação de mestrado, IEL/UNICAMP, 2004.

http://www.legiaourbana.com.br

http://www.conhecimentosgerais.com.br/historia-do-brasil/ sociedade-no-regime-militar.html

\section{Anexo}

\section{Faroeste Caboclo}

Letra e música: Renato Russo

Não tinha medo o tal João de Santo Cristo

Era o que todos diziam quando ele se perdeu

Deixou pra trás todo o marasmo da fazenda

Só pra sentir no seu sangue o ódio que Jesus the deu

Quando criança só pensava em ser bandido

Ainda mais quando com tiro de soldado o pai morreu

Era o terror da cercania onde morava

E na escola até o professor com ele aprendeu

la pra igreja só pra roubar o dinheiro

Que as velhinhas colocavam na caixinha do altar

Sentia mesmo que era mesmo diferente

Sentia que aquilo ali não era o seu lugar

Ele queria sair para ver o mar

$\mathrm{E}$ as coisas que ele via na televisão

Juntou dinheiro para poder viajar

E de escolha própria escolheu a solidão

Comia todas as menininhas da cidade

De tanto brincar de médico aos doze era professor

Aos quinze foi mandado pro reformatório

Onde aumentou seu ódio diante de tanto terror

Não entendia como a vida funcionava

Descriminação por causa da sua classe e sua cor

Ficou cansado de tentar achar resposta

E comprou uma passagem foi direto a Salvador

E lá chegando foi tomar um cafezinho

$E$ encontrou um boiadeiro com quem foi falar

$\mathrm{E} o$ boiadeiro tinha uma passagem

la perder a viagem mas João foi lhe salvar:

Dizia ele "Estou indo pra Brasília 
Nesse país lugar melhor não há

Tô precisando visitar a minha filha

Eu fico aqui e você vai no meu lugar"

E João aceitou sua proposta

E num ônibus entrou no Planalto Central

Ele ficou bestificado com a cidade

Saindo da rodoviária viu as luzes de natal

"Meu Deus mas que cidade linda!

No Ano Novo eu começo a trabalhar"

Cortar madeira aprendiz de carpinteiro

Ganhava cem mil pro mês em Taguatinga

Na sexta-feira foi pra zona da cidade

Gastar todo o seu dinheiro de rapaz trabalhador

$\mathrm{E}$ conhecia muita gente interessante

Até um neto bastardo do seu bisavô

Um peruano que vivia na Bolívia

E muitas coisas trazia de lá

Seu nome era Pablo e ele dizia

Que um negócio ele ia começar

E Santo Cristo até a morte trabalhava

Mas o dinheiro não dava pra ele se alimentar

E ouvia às sete horas o noticiário

Que dizia sempre que seu ministro ia ajudar

Mas ele não queria mais conversa

E decidiu que como Pablo ele ia se virar

Elaborou mais uma vez seu plano santo

E sem ser crucificado a plantação foi começar

Logo, logo os malucos da cidade

Souberam da novidade

"Tem bagulho bom ai!"

E João de Santo Cristo ficou rico

E acabou com todos os traficantes dali

Fez amigos, freqüentava a Asa Norte

la pra festa de Rock pra se libertar

Mas de repente

Sob uma má influência dos boyzinhos da cidade

Começou a roubar

Já no primeiro roubo ele dançou

$E$ pro inferno ele foi pela primeira vez

Violência e estupro do seu corpo

58 VOLUME 2, NÚMERO 2, 2006 
"Vocês vão ver, eu vou pegar vocês!"

Agora Santo Cristo era bandido

Destemido e temido no Distrito Federal

Não tinha nenhum medo de polícia

Capitão ou traficante, Playboy ou general

Foi quando conheceu uma menina

E de todos os seus pecados ele se arrependeu

Maria Lúcia era uma menina linda

E o coração dele pra ela o Santo Cristo prometeu

Ele dizia que queria se casar

E carpinteiro ele voltou a ser

"Maria Lúcia eu pra sempre vou te amar

E um filho com você eu quero ter"

O tempo passa

E um dia vem na porta um senhor de alta classe com dinheiro na mão

E ele faz uma proposta indecorosa

E diz que espera uma resposta, uma resposta de João

"Não boto bomba em banca de jornal

E nem em colégio de criança

Isso eu não faço não

E não protejo general de dez estrelas

Que fica atrás da mesa com o cu na mão

E é melhor o senhor sair da minha casa

Nunca brinque com um peixe de ascendente escorpião"

Mas antes de sair, com ódio no olhar

$O$ velho disse:

"Você perdeu a sua vida, meu irmão!"

"Você perdeu a sua vida, meu irmão"

"Você perdeu a sua vida, meu irmão"

Essas palavras vão entrar no coração

"Eu vou sofrer as consequêencias como um cão."

Não é que o Santo Cristo estava certo

Seu futuro era incerto

E ele não foi trabalhar

Se embebedou e no meio da bebedeira

Descobriu que tinha outro trabalhando em seu lugar

Falou com Pablo que queria um parceiro

Que também tinha dinheiro e queria se armar

Pablo trazia o contrabando da Bolívia 
E Santo Cristo revendia em Planaltina

Mas acontece que um tal de Jeremias Traficante de renome apareceu por lá

Ficou sabendo dos planos de Santo Cristo

$\mathrm{E}$ decidiu que com João ele ia acabar.

Mas Pablo trouxe uma Winchester 22

E Santo Cristo já sabia atirar

E decidiu usar a arma só depois

Que Jeremias começasse a brigar

Jeremias maconheiro sem vergonha

Organizou a Rockonha e fez todo mundo dançar

Desvirginava mocinhas inocentes

E dizia que era crente mas não sabia rezar

E Santo Cristo há muito não ia pra casa

$E$ a saudade começou a apertar

"Eu vou me embora, eu vou ver Maria Lúcia

Já está em tempo de a gente se casar"

Chegando em casa então ele chorou

$E$ pro inferno ele foi pela segunda vez

Com Maria Lúcia Jeremias se casou

E um filho nela ele fez

Santo Cristo era só ódio pro dentro

E então o Jeremias pra um duelo ele chamou

"Amanhã, as duas horas na Ceilândia

Em frente ao lote catorze é pra lá que eu vou

$E$ você pode escolher as suas armas

Que eu acabo com você, seu porco traidor

E mato também Maria Lúcia

Aquela menina falsa pra que jurei o meu amor"

E Santo Cristo não sabia o que fazer

Quando viu o repórter da televisão

Que a notícia do duelo na TV

Dizendo a hora o local e a razão

No sábado, então as duas horas

Todo o povo sem demora

Foi lá só pra assistir

Um homem que atirava pelas costas

E acertou o Santo Cristo

E começou a sorrir

60 VOLUME 2, NÚMERO 2, 2006 
Sentindo o sangue na garganta

João olhou as bandeirinhas

E o povo a aplaudir

E olhou pro sorveteiro

E pras câmeras e a gente da TV que filmava tudo ali

E se lembrou de quando era uma criança

$E$ de tudo o que viveu até aqui

$E$ decidiu entrar de vez naquela dança

"Se a via-crucis virou circo, estou aqui."

E nisso o sol cegou seus olhos

E então Maria Lúcia ele reconheceu

Ela trazia a Winchester 22

A arma que seu primo Pablo lhe deu

"Jeremias, eu sou homem. Coisa que você não é

Eu não atiro pelas costas, não.

Olha pra cá filha da puta sem vergonha

D uma olhada no meu sangue

E vem sentir o teu perdão"

E Santo Cristo com a Winchester 22

Deu cinco tiros no bandido traidor

Maria Lúcia se arrependeu depois

E morreu junto com João, seu protetor

O povo declarava que João de Santo Cristo

Era santo porque sabia morrer

$\mathrm{E}$ a alta burguesia da cidade não acreditou na história

Que eles viram da TV

E João não conseguiu o que queria

Quando veio pra Brasília com o diabo ter

Ele queria era falar com o presidente

Pra ajudar toda essa gente que só faz

Sofrer

CONEXÃO LETRAS 61 